Portland State University

PDXScholar

1984

\title{
A validation study of the screening test for developmental apraxia of speech
}

Deborah L. Thorsen

Portland State University

Follow this and additional works at: https://pdxscholar.library.pdx.edu/open_access_etds

Part of the Speech Pathology and Audiology Commons

Let us know how access to this document benefits you.

\section{Recommended Citation}

Thorsen, Deborah L., "A validation study of the screening test for developmental apraxia of speech" (1984). Dissertations and Theses. Paper 3331.

https://doi.org/10.15760/etd.3311

This Thesis is brought to you for free and open access. It has been accepted for inclusion in Dissertations and Theses by an authorized administrator of PDXScholar. Please contact us if we can make this document more accessible: pdxscholar@pdx.edu. 
AN ABSTRACT OF THE THESIS OF Deborah L. Thorsen for the Master of Science in Speech Communication, with an emphasis in SpeechLanguage Pathology, presented April 20, 1984.

Title: A Validation Study of the Screening Test for Developmental Apraxia of Speech.

APPROVED BY MEMBERS OF THE THESIS COMMITTEE:

Mary E. Gordon, Chairperson

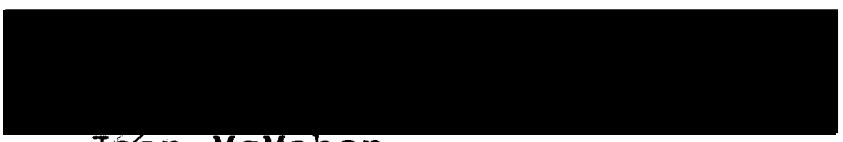

Lran McMahon

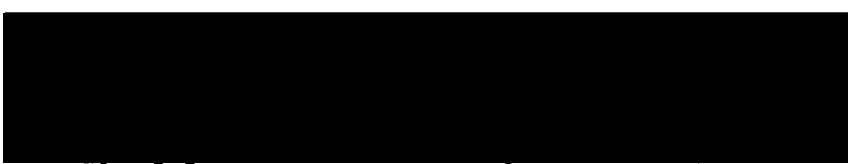

Sheldon Maron

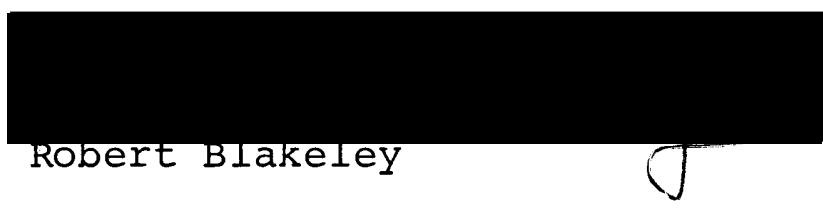

The term "developmental apraxia of speech" (DAS) has been a confusing one sine Morley, Court and Miller (1954) first applied it to articulatory patterns of a specific group of children. Until recently, the differentiation of diagnostic features of DAS in children as compared to other 
articulatory disorders has been difficult. One evaluation tool, developed by Blakeley (1980), to assist in differential diagnosis of DAS is the Screening Test for Developmental Apraxia of Speech (STDAS). This study examined the validity of this tool by comparing its results with the evaluations by three Speech-Language Pathologists knowledgeable in the area of developmental and/or acquired apraxia of speech.

Twenty subjects, ranging in age from 4-5 to 7-7 years, participated in this study. The subjects were independently screened by four evaluators. The first evaluation was conducted by this researcher, administering the STDAS to each subject. The other three evaluators screened each subject using their own procedures, excluding the STDAS. The STDAS resulted in a probability rating for DAS. The three evaluators were instructed to rate each subject on probability of DAS based upon their individual methods of assessment.

To determine the relationship between the three evaluator pairs $(B C, B D, C D$ ) the index of association used was the Pearson Product - Moment Correlation Coefficient (Pearson-r). The results indicated the evaluators only slightly agreed with one another. Although they were in general agreement as to what characteristics constitute DAS, their perceptions of each subject were quite varied.

In correlating the STDAS (A) with each evaluator (B, C, D) using the Pearson-r, the results ranged from slight correlation of $A B(.20)$ to high correlation of $A D(.73)$. This outcome may indicate that the STDAS tapped more of the 
components of apraxia (in the sense of comprehensiveness) than any single evaluator measure.

Two factors seemed to contribute to the varied results among evaluators: (1) lack of information about the subjects' history of development, including familial history and management history; and (2) varied amount of structure used among the evaluators. When comparing the STDAS results with an evaluator who used a highly structured method of assessment, the correlation was high. This evaluator had the advantage of objective data, as well as clinical judgment upon which to base the final rating for each subject.

The inconsistency among the evaluators' assessment results is an excellent argument for a screening instrument that uses the current body of knowledge concerning DAS. The STDAS forces the examiner to assess the child more objectively. The resulting data of this study support Blakeley's intention for the STDAS to be used as part of a differential diagnosis of DAS. When combined with other measures, such as case history, clinical judgment and neurological assessment, the STDAS can play an important contributing role in differentiating DAS from other articulatory disorders. 


\section{A VALIDATION STUDY}

OF THE

SCREENING TEST

FOR DEVELOPMENTAL APRAXIA OF SPEECH

by

DEBORAH THORSEN

A thesis submitted in partial fulfillment of the requirements for the degree of

MASTER OF SCIENCE IN SPEECH COMMUNICATION:

with an emphasis in

SPEECH-LANGUAGE PATHOLOGY

Portland State University 
TO THE OFFICE OF GRADUATE STUDIES AND RESEARCH:

The members of the Committee approve the thesis of Deborah Thorsen presented April 20, 1984.

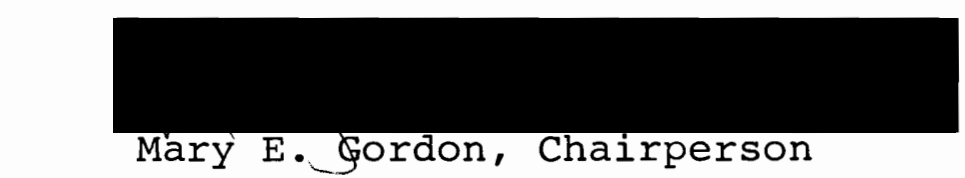

soan McMahon

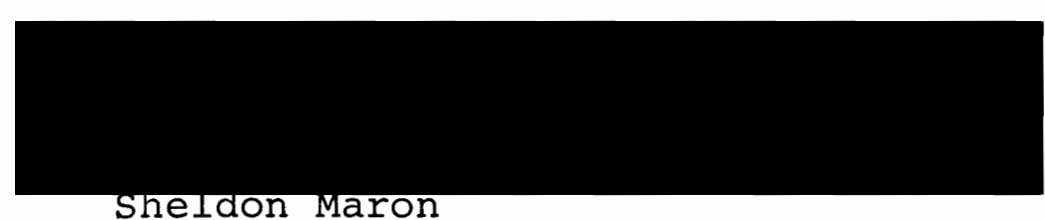

Shelaon Maron

APP ROVED :

Robert Blakeley

Theodore G. Grove, Chair, Department of Speech Communication

Stanley $\$$. Rauch, Dean, Graduate Studies and Research 


\section{ACKNOWLEDGEMENTS}

\section{A very special thanks to:}

Committee Members

Mary Gordon, Joan McMahon, Robert Blakeley and Sheldon Maron

$$
\text { Evaluators }
$$

Phil Levinson, Kathy Ware and Glenn Weybright

\section{Prospectus Critiquers}

Kathy Gray, Carol Kafton-Minkel, JoAnn Warlick

(JoAnn also gave me a moc Orals just prior to the real thing)

Graphics

Sharon Thorsen

Speech-Language Pathologists providing subjects from their caseloads

Karen Jenkins, Susan Leonti, Kathy McCausland, Lori Saltness, Joan Polson, Robyn Schwartz and Kristen Winn

Statistical Consultant

Ted Grove

Typist

Marilyn Caum

Love and support

My parents, Gene and Vi Thorsen and my neighbors Ron and Betty Hill

Wagging tail and wet kisses

In memory of my dog, Tauna, and in honor of my new dog, Lacey

The children and their families who participated in this study and my first client at PSU, Speech and Hearing Clinic,

$$
\text { Don, }
$$

who inspired it all. 
TABLE OF CONTENTS

Page

ACKNOWLEDGEMENTS

iii

LIST OF TABLES

LIST OF FIGURES

CHAPTER

I INTRODUCTION AND STATEMENT OF PURPOSE

Introduction ............. . 1

Statement of Purpose . . . . . . . . . 3

Definitions .. . . . . . . . . . . 4

II REVIEW OF THE LITERATURE 5

Incidence and Etiology of DAS . . . . 5

Characteristics of DAS . . . . . . . . . . 7

Assessment of DAS . . . . . . . . . . . 12

Implications for Management of DAS . . . 15

$\begin{array}{ll}\text { III METHODS AND PROCEDURES } & 17\end{array}$

General Plan ............. 17

Subjects . . . . . . . . . . . . . 17

Evaluators .............. 18

Measurement Instruments ....... 20

Testing Procedures .......... . 23

Data Scoring and Analysis . . . . . 24

IV RESULTS AND DISCUSSION 26

Results ............... 26

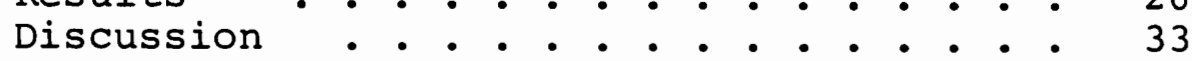

$\begin{array}{lll}\mathrm{V} & \text { SUMMARY AND IMPLICATIONS } & 38\end{array}$

Summary •. • • • • • • • • • • • 38

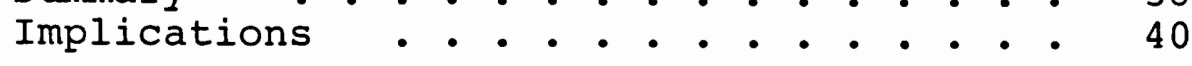

REFERENCES ..................... . . . 43 


\section{LIST OF TABLES}

TABLE

Page

I Summary of Subjects Probability Percentage

Ratings from the STDAs and the Evaluators

B, C, and D . . . . . . . . . . .

II Resulting Pearson-r's, Standard Deviations and

Means of the Three Independent Evaluator

Pairs (BC, $\mathrm{BD}, \mathrm{CD})$. . . . . . . .

III Resulting Pearson-r's, Standard Deviations

and Means between the STDAS Ratings and

the Independent Ratings of the Three

Evaluators . . . . . . . . . . .

IV A Correlation Matrix of the Five Variables

Showing the Strength of Association

between All Possible Pairs ......

$V$ Results of the $t$-Test of the Differences between

the STDAS and the Independent Measures of

the Evaluators

VI Direction of Disagreement from the STDAS . .

VII Percent Each Evaluators' Scores Were in

Agreement with STDAS Scores Ranging

from Absolute Agreement to Low

Agreement 


\section{LIST OF FIGURES}

FIGURE

Page

1. The Index of Determination . . . . . . . . 31 


\begin{abstract}
CHAPTER I
INTRODUCTION AND STATEMENT OF PURPOSE
\end{abstract}

Introduction

The term "developmental apraxia of speech" (DAS) has been a confusing one since Morley, Court and Miller (1954) first applied it to articulatory patterns of a specific group of children.

The lack of well-defined research on DAS has even led to controversy over the existence of this disorder (Haynes, 1978; Guyette and Diedrich, 1983). To add to the confusion, terminology has been varied. Morley (1965) used two terms to describe this disorder, "developmental articulatory dyspraxia" and "developmental dyspraxia." Ferry, Hall and Hicks (1974) described it as "delapidated speech." Other labels have included oral apraxia and verbal dyspraxia (Weiner, 1969) and a "disorder of volition" (Rosenbek, Hansen, Baughman and Lemme, 1974). Characteristics of children labled with such terms include highly unintelligible speech, failure to improve even with extensive intervention, hearing within normal limits, age appropriate receptive language, and groping and struggling to achieve correct positioning of the articulators (Ferry et al., 1974). The literature thus far agrees it is a disorder primariliy of articulation (Yoss and Darley, 1974a 
and b; Haynes, 1978; Blakeley, 1980).

Until the present time, the differentiation of diagnostic features of DAS in children as compared with those of functional articulation disorders has been difficult. Consequently, many children with this serious disorder continue to be categorized as displaying functional articulation disorders. Functional articulation disorders (FAD), according to Bernthal and Bankson (1981), has become a "catch-all" term often including all children with articulation errors of unknown causes. Bernthal and Bankson emphasize that an articulation disorder of unknown etiology may be caused by one or more subtle organic, learning or environmental factors. They speculate that as more exacting assessment instruments are developed, fewer children may be diagnosed as having functional articulation disorders. According to Johnson (1980), the difficulty in diagnosing DAS may be due to the fact that (1) the phonological systems in children have not matured, which results in both phonetic and phonemic errors and (2) the neuropathology is unclear and not well defined. Accurate diagnosis is crucial because remediation of DAS is more complex than that most often used with children having other articulatory disorders (Aten, Johns and Darley, 1971; Yoss and Darley, 1974a; Dabul and Bollier, 1976; Darley and Spriestersbach, 1978). Intervention for DAS must be child and symptom specific, requiring a long-term daily commitment (Haynes, 1978; Blakeley, 1980; Johnson, 1980). One evaluation tool, developed by Blakeley (1980), to 
assist in the differential diagnosis of DAS is the screening Test for Developmental Apraxia of Speech (STDAS). The STDAS consists of eight subtests, including expressive language discrepancy, vowels and diphthongs, oral-motor movement, verbal sequencing, articulation proficiency, motorically complex words, transpositions and prosody. According to Blakeley, the STDAS is intended to differentiate DAS from other articulatory disorders; it is not designed to diagnose DAS but to determine the need for further investigation. The STDAS has face validity, according to Blakeley, as it was developed from (1) a review of the literature regarding characteristic descriptions of DAS (2) clinical experience and (3) support by other experts in the field, including two of Blakeley's colleagues (see acknowledgements in Blakeley, 1980). Further validation of the STDAS as a useful screening tool would be of great benefit for the identification of DAS in children.

\section{Statement of Purpose}

The purpose of this study was to correlate the results of the Screening Test for Developmental Apraxia of Speech with the evaluations by three Speech-Language Pathologists, who have a current working knowledge of the disorder of developmental and/or acquired apraxia of speech, in order to determine the construct validity of the STDAS as a predictor of DAS in children with defective articulation. The question this study sought to answer was: 
Is the Screening Test for Developmental Apraxia of Speech a valid predictor of DAS in Children when correlated with independent evaluations by three speechLanguage Pathologists, with a current working knowledge of the disorder of developmental and/or acquired apraxia of speech?

\section{Definitions}

The following definitions will be utilized throughout this study:

Apraxia: "...an inability to perform a skilled voluntary act despite absence of paresis or incoordination of muscular control" (Darley, 1964).

1. Acquired Apraxia of Speech: An articulatory disorder as a result of brain damage which impairs the capacity to program the positioning of speech muscles and the sequencing of muscle movements for the volitional production of phonemes. No significant weakness, slowness, or incoordination of these muscles in reflex and automatic acts. Prosodic alterations may be associated with the articulatory problem, perhaps in compensation for it (Darley, 1969).

2. Developmental Apraxia of Speech (DAS): DAS is an inability to perform voluntary movements of the muscles involved in articulation, although automatic movements of the same muscles are preserved (Morley, 1965). Onset occurs prior to normal articulation development (Horowitz, 1979).

3. Oral Apraxia: A disorder in voluntary movements of the muscles of the larynx, pharynx, tongue, lips and palate (Mitcham, 1975).

4. Verbal Apraxia: A disorder in the mechanics of correct verbal formation in which an individual cannot correctly set the speaking processes into motion (Mitcham, 1975).

Functional Articulation Disorder (FAD): "...an inability to produce correctly all of the standard speech sounds of the language for which there is no appreciable structural, physiological or neurological basis in the speech mechanism or its supporting structures, but which can be accounted for by normal variations in the organism or by environmental or psychological factors" (Powers, 1971). 
CHAPTER II

REVIEW OF THE LITERATURE

Morley et al. (1954) were the first to apply the term Developmental Apraxia of Speech (DAS) to a specific group of children. Since then, researchers have been examining the question of how these children differ from those with other articulatory disorders. Organic disorders of articulation associated with cerebral palsy or cleft palate are obvious in their distinctions, but the distinction between functional articulation disorders (FAD) and DAS is not so clear.

Although a review of the literature indicates a growing support of the existence of the disorder of DAS and agreement on specific characteristics, there are still those who doubt the existence of such a disorder at all (Haynes, 1978; Blakeley, 1982; Guyette and Diedrich, 1983).

\section{Incidence and Etiology of DAS}

According to Weiss, Lillywhite and Gordon (1980), articulation disorders constitute over 60 percent of all communication disorders. A typical public school caseload is comprised of 75-80 percent articulation disorders with DAS a significant percent of that (Johnson, 1980; Wolfe and Goulding, 1980). These researchers did not specify the significant percentage of DAS children within the public school 
caseload; however, several years earlier Ferry et al. (1974) estimated that 10 percent of all school age articulation problems were a result of DAS. They also found the ratio of males to females diagnosed as having DAS to be 3 to 1 . According to Ferry et al., DAS is first seen in children ages 2 years, 5 months to 9 years and is often associated with a familial history of speech diorders.

Through the years researchers have been attempting to localize the exact area in the brain where insult had occurred resulting in apraxic characteristics (Mitcham, 1975). Wertz, Rosenbek and Deal (1970) studied 108 patients with acquired apraxia of speech. Of the 108, 49 had lesions in the third frontal convolution (Broca's area) and 59 had lesions in other areas of the brain. Specific localization was not supported by this study. In children, wertz et al. (1970) suggested identification of localization is even more difficult than in adults. They rationalized that children with DAS, for the most part, are normal and little opportunity for post-mortem examination has made it difficult to examine malfunctioning brain tissue.

There appears, however, to be general agreement among researchers that DAS is not a functional articulation disorder, but an articulation disorder subsequent to neurological impairment (Edwards, 1973; Rosenbek, et al., 1974; Darley, Aronson and Brown, 1975; Prichard, Tekieli and Kozup, 1979; Weiss et al., 1980) . Ferry et al. concurred that DAS is an impairment of neural and 
muscular functioning. They hypothesized that DAS may be a result of brain damage incurred prior to birth. The intricate neural connections linking the articulators to the brain may be disturbed during development.

Silverstein (1971) reported that children with articulation disorders, previously classified as functional, may have neurological etiology. To be more specific, Haynes (1978) suggested that careful examination of children with persisting, single-sound substitutions, such as $/ r /$ and $/ s /$, as well as those with multiple articulation errors may reveal motor planning deficits that are in greater numbers than previously suspected. Mitcham (1975) concluded that observation of behavioral characteristics would be the most helpful in planning intervention than attempts at localization of the disorder of DAS.

As mentioned earlier, FAD has been used as a "catch-all" term for articulation errors of unknown etiology (Bernthal and Bankson, 1981). The assumption is there is no physical cause (Weiss et al., 1980) and as Powers (1971) suggested, children are labeled by default because there is no obvious cause. The current state of the art does not permit absolute etiological classification and an articulation disorder of unknown etiology may be caused by subtle organic, learning or environmental factors.

\section{Characteristics of DAS}

Mitcham (1975) was of the opinion that some children 
displaying DAS characteristics, at the time of her study, were treated as FAD in the public school caseloads. It is the opinion of this author that the same may be true even today. To ensure correct diagnosis of DAS, clinicians must be familiar with the characteristics of DAS in order initially to identify those children. The following section describes characteristics most often mentioned in the literature by which DAS may be recognized.

Eisensen (1972), in describing the early oral activity of children with DAS, found that early vocal play was either absent or only minimumly present. He found that acquisition of speech was delayed as well.

Rosenbek and Wertz (1972) found children having DAS to be within the range of normal intelligence and reported their receptive language abilities to be far superior to their expressive language abilities. They emphasized that this characteristic was not common in FAD and indicate this difference is beneficial in recognizing DAS in children. Other characteristics outlined by Rosenbek and Wertz are as follows: (1) delayed and deviant speech development, (2) the possible presence of an oral apraxia, (3) phonemic errors more often in the form of sound omissions, (4) metathetic errors (e.g., batsek for basket), (5) an increase in errors with increased word length, (6) connected speech much poorer than single word productions, (7) errors more frequently occurring on the more complex fricatives, affricatives, and consonant clusters, (8) highly inconsistent error paterns, (9) prosodic 
disturbances and (10) groping or trial-and-error behavior or silent posturing.

Yoss and Darley (1974a) conducted a study designed to identify behavior characteristics which might distinguish DAS from FAD. They concluded from their research that there is a subgroup of children whose performance supports the use of the term "developmental apraxia of speech" as descriptive of their articulatory disorder. Chararcteristics outlined by Yoss and Darley include: (1) difficulty with volitional movements of oral musculature, (2) two and three feature errors, particularly involving voicing, (3) slower than normal oral disdochokinesis rates, (4) greater difficulty with polysyllabic words and (5) altered prosody. They also reported 94 percent of the children in the DAS group presented "soft" neurologic evidence which characterized them as developmentally immature to some degree. These "soft" signs, in their opinion, did not imply a pathologic condition of the central nervous system nor minimal brain dysfunction. The "soft" signs most often found were decreased alternate motion rates of the tongue and extremities.

Williams, Rosenthal and Ingham (1978) partially replicated the Yoss and Darley (1974a) study after attempting to use the variables identified by them to confirm diagnosis of DAS in children. They found that children tentatively diagnosed as "apraxic" by clinicians did not necessarily exhibit "soft" neurological signs and errors of articulation outlined by Yoss and Darley. Their findings did not agree with those 
reported by Yoss and Darley, which prompted a larger study conducted by Williams, Ingham and Rosenthal (1981a). The findings of this study also differed from those reported by Yoss and Darley. Williams et al. concluded that Yoss and Darley may have sampled a population of articulation-disordered children who also demonstrated "soft" neurological signs and their study may have examined another articulation disordered population having no such "soft" neurological signs, but like Yoss and Darley's study, exhibited difficulty with oral volitional movements.

Another factor in the lack of agreement in the Williams et al. (1981a) and the Yoss and Darley (1974a) studies may be that both methods did not include an attempt to determine whether the target group of children were described by clinicians as displaying DAS. In other words, there would be some advantage in determining whether those who claim to be able to identify such a disorder, namely speech-language clinicians, are able to agree on the behaviors that they describe as constituting DAS. Williams, Packman, Ingham and Rosenthal (1981b) conducted a study designed to find some agreement among speech-language clinicians on behaviors they judged distinguished DAS. They sent a questionnaire to 31 speechlanguage clinicians who practiced in child clinics in sidney, Australia. The clinicians were instructed to respond to a questionnaire which asked them to classify 21 behaviors as "always," "sometimes," or "never" associated with one of three types of articulation disorders, i.e., functional, 
dyspraxic (DAS), or organic. Four behaviors listed were agreed upon to be associated only with DAS: (1) articulation development that was deviant rather than immature, (2) searching behavior in attempting some (or all) target phonemes, (3) inconsistent pattern of phoneme errors and (4) inability to produce volitionally an isolated phoneme, or sequence of phonemes, which had been produced previously. The following eight behaviors positively associated with DAS were also positively associated with one or both of the other two disorders (functional and/or organic): (1) client is able to produce required phonemes on diadochokinetic tasks but with abnormally slow rate, (2) client's speech contains phoneme substitution errors, (3) client omits some (or all) phonemes in pre-vocalic, post-vocalic and inter-volcalic positions in words, (4) in a connected speech task, the client is able to incorporate a target phoneme at slower than normal speech rate but is unable to do so at normal speech rate, (5) at some time in the treatment program for some (or all) target phonemes, client displays inability to progress from one step to the next, e.g., from syllable to word, (6) client demonstrates error of voicing on some (or all) phonemes, (7) client shows inability to produce the correct sequence of phonemes on the diadochokinetic task, "peteke," although able to produce the required phonemes in isolation, and (8) client's speech contains vowel distortions (i.e., vowel is perceived as the required phoneme but is slightly off target). Children with DAS, according to Haynes (1978), display 
a lack of awareness of articulatory positions and often use telegraphic speech. Haynes emphasized that remediation programs were usually prolonged, but found that performance improved when visual feedback was used.

Morley (1965) was more specific in her description of DAS by saying that children produced a limited amount of consonants and had less difficulty on vowels. She observed that consonant clusters were more difficult than singletons. She also found that children with DAS transposed sounds and syllables, which was not characteristic of children with FAD.

Studies of acquired apraxia have revealed some similar behaviors to those children with DAS (Yoss and Darley, 1974a). In fact, such studies prompted the research of children exhibiting these similar behaviors. The differences outlined by Yoss and Darley are worth noting here. They are: (1) an accompanying oral apraxia is usually apparent in children, (2) audible groping and effortful trial and error, searching for the correct placement of the articulators are not evident in children, unless they are older, (3) more multiple features are characteristic of the speech production pattern of adults and (5) children do not appear to be aware of their articulation errors, unless they are older or have extensive management histories.

Assessment of DAS

An articulation disorder may be symptomatic of an 
underlying disturbance in biology, environment or a number of minor disturbances that collectively prevent an individual from acquiring normal articulation functioning (Johnson, 1980). In order to prevent insufficient and inappropriate program management and frustration on the part of the child and clinician, an understanding of the underlying disturbance is essential. To do this, appropriate assessment procedures must be employed.

Darley (1975) pointed out there are a number of tests available to assess the articulatory proficiency of children. Generally, these tests are designed to sample the child's performance on all of the consonant phonemes with some testing vowels and diphthongs as well. Weiss et al. (1980) have found that traditional diagnostic procedures have not incorporated a differential or client specific approach; the same tools have been used regardless of etiology. Traditional single word testing, Weiss et al. contended, ignores the factors of difficulty in sequencing, effortful articulation, dysprosody, difficulty in nonspeech movements of articulators, imitation of later-developing consonants, self-monitoring skills and memory for articulation movement and position. Haynes (1978) suggested a test battery include tools for the assessment of the following: (1) language ability, (2) articulatory proficiency and the phonetic influences, (3) oral diadochokinesis, (4) volitional movements of the oral musculature, and (5) orosensory perception.

In Yoss and Darley's study (1974a), the test battery 
examined five aspects of behavior: (1) auditory perception and discrimination, (2) execution of sequenced and isolated volitional oral movements, (3) phoneme production in spontaneous contextual speech, (4) phoneme production in real and nonsense words and (5) oral diadochokinetic rate. In addition to these five tests, each subject received a complete neurologic examination.

The study conducted by Mitcham (1975) also consisted of a test battery for DAS, in which she combined portions of the Yoss and Darley (1974a) battery of tests for apraxia in children and one for acquired apraxia in adults by Wertz and Rosenbek (1970). Mitcham's battery included a verbal and nonverbal section. Areas tested were: (1) vowel production, (2) diadochokinesis, (3) multisyllabic words, (4) words of increasing length, (5) initial-final phoneme comparison, (6) sentences, (7) spontaneous speech, (8) imitative speech, (9) automatic speech, (10) volitional oral movements and (11) limb apraxia. This battery was administered in approximately 40 minutes.

Prior to 1980, no formal evaluative format using the current body of knowledge concerning DAS has been available. Blakeley (1980) considered this fact and surmised a screening tool could have considerable value in leading to diagnosis and subsequently, to an appropriate management program for children with DAS.

Considering the available test batteries and the characteristics agreed upon in the literature, clinical 
experience and availability of normative data, Blakeley developed the Screening Test for Developmental Apraxia of

Speech. The test can be administered in approximately 10 minutes, which makes it very useful in a public school setting. The STDAS is the only formal screening tool of DAS to date.

\section{Implications for Management of DAS}

Ferry et al. (1974) estimate approximately 10 percent of all school age articulation disorders in the United states are a result of DAS. Weiss et al. (1980) predict 60 percent of all communication disorders are articulation disorders. When these two predictions are combined, approximately 15,000 children exhibiting DAS characteristics in the United States are in need of specialized management other than the traditional approaches.

Traditional articulation management approaches have primarily focused on auditory discrimination tasks (Johnson, 1980). Mitcham (1975) pointed out that children with DAS have poor auditory skills and, therefore, the traditional approaches are generally not effective with such children. She stressed the importance of assessing the individual child's needs when designing a mangement program.

Darley et al. (1975) suggested the main goal for these children is to help them gain voluntary, accurate control in programing the position of their articulators to produce phonemes and phoneme sequences. In order to do this, direct 
management on those phonemes and their sequences is needed. Haynes (1978) has drawn together some suggestions for remediation from a review of the literature on acquired apraxia, as well as general articulation principles. Some of those suggestions are as follows: (1) concentrated drill on performance, both in imitation and on command, of tongue and lip movement, (2) imitation of sustained vowels and consonants, followed by production of simple syllable shapes, (3) use of movement patterns and sequencing of sounds, (4) avoidance of auditory discrimination drills, (5) increase slow rate and self-monitoring skills, (6) use of a core vocabulary, (7) use of carrier phrases, (8) use of rhythm, intonation and stress paired with motor movement, (9) intensive, frequent and systematic drill, (10) increase skills in orosensory perceptual awareness, (11) utilize all sensory modalities and, (12) daily sessions (or 3-4 days per week) (Rosenbek et al, 1974; Yoss and Darley, 1974b; Haynes, 1978; Johnson, 1980; Weiss et al., 1980; and Gordon, 1982).

Speech-language pathologists must familiarize themselves with DAS characteristics and intervention strategies from the literature in order to identify and treat children with DAS appropriately. 
CHAPTER III

METHODS AND PROCEDURES

General Plan

Subjects meeting the criteria for inclusion in this study were administered the Screening Test for Developmental Apraxia of Speech (STDAS) developed by Blakeley (1980). The result of each STDAS was converted to a weighted score, which in turn was located on a graph indicating with what probability each subject belonged to an apraxic group (see Appendix A). Each subject was then independently evaluated by three Speech-Language Pathologists with a current working knowledge of the disorder of apraxia of speech. The evaluators used their own evaluative procedures, excluding the use of the STDAS, and then rated each subject on a scale from 0 to 100 percent, as to their probability of belonging to an apraxic group. The results of the STDAS and the Speech-Language Pathologists' evaluations were then correlated (see Table 1).

\section{subjects}

Twenty subjects were selected from the Portland, Oregon Public School District; North Clackamas, Oregon School District; Battle Ground, Washington School District and the files from the Portland State University Speech and Hearing 
clinic. The parents of each potential subject signed a release form for participation in this study (see Appendix B). The subjects ranged in age from 4.5 to 7.7 years and were previously or presently enrolled in a school or clinic speech intervention program. In addition, all subjects selected met the following criteria:

1) Hearing within normal limits in one ear based on audiometric screening test for the frequencies of $500,1000,2000$, and $4000 \mathrm{~Hz}$ at $25 \mathrm{~dB} \mathrm{HL}$ (re: ANSI 1969)

2) A receptive language age at or above the loth percentile according to the Peabody Picture Vocabulary Test - Revised, Form L (Dunn, 1981)

3) No known organic disorder which might be a significant contributing factor to an articulation problem, such as, cerebral palsy or cleft palate, based on information in the child's clinic or school records and/or parent report.

4) Misarticulated, consistently or inconsistently, four or more separate and distinct phonemes as determined by the Arizona Articulation Proficiency Scale - Revised (Fudala, 1982).

\section{Evaluators}

Three speech-language pahtologists from the greater Portland area were selected as evaluators for this investigation. One evaluator was from the Portland Center for Hearing and Speech, another from the Scottish Rite Institute for Childhood Aphasia and a third from Emanuel Hospital. They met the following criteria:

1) At least five years clinical experience in the field of Speech-Language Pathology

2) Currently practicing in the field of Speech-Language Pathology 
3) Hold a Master's or higher degree and Certificate of Clinical Competence, awarded by the American Speech-Language and Hearing Association

4) Possess a current working knowledge of the disorder of developmental and/or acquired apraxia of speech.

Evaluator Background

Evaluator B has ten years experience as a speech-language pathologist. This experience included an average of two apraxic preschool children per year. This experience has included both assessment and intervention.

Evaluator $C$ has ten years of experience as a speech-language pathologist. Two of those years were spent teaching and eight in clinical training and direct clinical service. Courses taught contained information about the diagnosis and management of developmental aptaxia of speech. Evaluator C has supervised students providing service to developmentally apraxic children and has provided clinical services to several developmentally apraxic children during the past two and one-half years.

Evaluator D has worked for five years extensively in the evaluation and treatment of acquired apraxia, primarily with adults. Graduate studies included work with Sara Macaluso-Haynes, M.S. at the University of Texas at Dallas. Ms. Haynes wrote a chapter on "Developmental Apraxia of Speech" in the text Clinical Management of Neurogenic Communication Disorders, edited by Johns (1978). 
Measurement Instruments

The Screening instruments used in this investigation are described below:

1) Beltone Portable Audiometer, Model 10-D. This is a wide range audiometer that utilizes the frequency range $125-8000 \mathrm{~Hz}$. It was calibrated monthly according to ANSI 1969 and utilized Beltone earphones.

2) Peabody Picture Vocabulary Test - Revised, Form L (PPVT-R) (Dunn, 1981). This test was designed to estimate a subject's vocabulary recognition age level. This nonverbal vocabulary recognition test consists of a book of plates with each plate containing four pictures. The subject was instructed to point to one of the four pictures based on a word presented verbally by the examiner. The scoring was based on a basal and ceiling system.

3) Arizona Articulation Proficiency Scale - Revised (AAPS-R) (Fudala, 1982). This test consists of 48 Picture Test Cards, each with a simple line drawing of an object common to a child's vocabulary. A child responds to the pictures by labeling them verbally. The AAPS-R provides a scale of articulatory proficiency, using numerical values for sounds relating to their probable frequency of occurrence in Standard American English.

The experimental tools included the STDAS and the evaluation procedures by the three speech-language pathologists. The STDAS was developed to help in the differential diagnosis of DAS. It consists of eight subtests, which are described below:

Subtest I: Expressive Language Discrepancy

The subject's expressive language age was compared to his/her language comprehension age to determine the discrepancy often accompanying DAS. In this study, the PPVT-R was used to determine language comprehension age and the subject's Mean Length Utterance was used to determine his/her expressive language age. 
McCarthy's Mean Length Utterance (MLU) was used to measure the subject's verbal output and linguistic achievement. The examiner transcribed verbatim a 50-utterance language sample during play of each subject.

Subtest II: Vowels and Diphthongs

The subject was instructed to imitate words containing vowels and diphthongs presented by the examiner.

Subtest III: Oral-Motor Movement

The subject was instructed to imitate nonspeech oral movements using his/her tongue and lips.

Subtest IV: Verbal sequencing

Verbal sequencing refers to placement of syllables in proper order over a period of time. The sounds $/ \mathrm{p} /, / \mathrm{t} /$, and $/ \mathrm{k} /$ were paired with the vowel / $/ \wedge /$ and presented verbally in different orders to the subject. This subtest consists of two parts. Part A combines the three sounds to make three syllables,

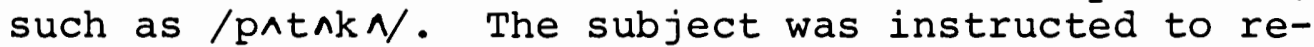
peat the three syllables presented by the examiner and given five trials to do so correctly. In part $B$ the three sounds were presented in three sets of

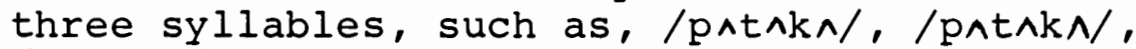

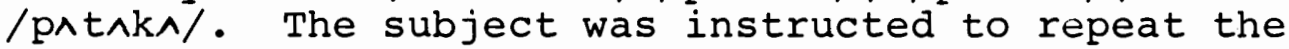
three sets of three syllables and given three trials to do so correctly.

Subtest V: Articulation

The subject was instructed to imitate words presented by the examiner. Besides marking substitutions, omissions and distortions, errors in phonemic characteristics and their position were also marked.

Subtest VI: Motorically Complex Words The subject was instructed to imitate three multisyllabic words presented verbally by the examiner. The subject was given three trials to imitate the word using correct sound and syllable order.

Subtest VII: Transpositions

On this subtest the examiner was looking for reversals the subject might make on words that are provocative of transpositions. The subject was instructed to imitate a word presented by the examiner and was allowed one trial. The actual production was then transcribed phonetically.

Subtest VIII: Prosody

Short samples of the subject's connected speech were observed. The examiner then subjectively evaluated 
the subject's prosody on a 3-point scale.

The three speech-language pathologists (evaluators) used their own procedures for evaluating the subjects. A description of each of the evaluators procedures follows.

Evaluator B's informal screening battery for suspected apraxic involvement consisted of:

1) informal administration of the Developmental Articulation Test (Hejna, 1963);

2) imitation of 10-12 vowels and diphthongs;

3) three repeated imitations of the same multisyllabic word (e.g., toothbrush);

4) repeated imitations of 2 and 3 syllable nonsense utterances;

5) estimate of general intelligibility and a comparison of that with child's age;

6) imitation of non-speech oral-motor movements;

7) consistency/inconsistency of articulation errors;

8) length and complexity of verbal output.

Evaluator C's procedures consisted of:

1) determining general level of intelligibility and consistency of errors;

2) assessing ability to imitate oral-motor movements ;

3) for children 5 years of age and older assessing

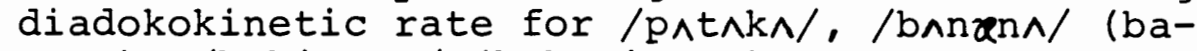
nana), /bebisit5/ (babysitter);

4) assessing single word articulation by using the Arizona Articulation Proficiency Scale - Revised (Fudala, 1982) and assessing stimulability for error sounds.

Evaluator D developed a structured screening tool which was used for each subject. This measure was the most objective of the three evaluator procedures. This tool consisted of the following items: 
1) prolongation of vowel sounds ah, ee, oo;

2) rapid repetition of the syllables $/ \mathrm{p} \wedge /, / \mathrm{t} \wedge /$, $/ \mathrm{k} \wedge /$;

3) imitation of multisyllabic words;

4) imitation of words of increasing complexity (e.g., thick, thicker, thickening);

5) imitation of CVC words (judge, peep, sis, church, zoos, lull, shush, coke, gag and dad);

6) sentence repetition;

7) spontaneous speech sample;

8) repetition of three sentences produced spontaneously by subject;

9) count to 20;

10) assessing of oral-motor movements;

11) two-item sequencing task (e.g., tongue out, smile) ;

12) three-item sequencing task (e.g., chatter teeth, lick lips, clear throat);

13) assessing of limb movements (e.g., wave goodbye, salute).

\section{Testing Procedures}

Setting

All testing was conducted in quiet, well-lighted rooms at Portland State University Speech and Hearing Clinic or the subject's school. The subjects were examined one at a time with distractions held to a minimum during the examination session.

Screening

The subjects were first screened to determine their appropriateness for this study. The screening began with a puretone hearing test. The PPVT-R, Form L (Dunn, 1981) was then administered. This was followed by the AAPS-R (Fudala, 
1982). A break was then given to the subject as the examiner quickly reviewed the results to determine if the subject met criteria for inclusion in this study.

Experimental evaluation

If the subject did meet criteria, a 50-utterance language sample was taken in a play situation, requiring approximately 15 minutes. The final test to be administered by the examiner was the STDAS (Blakely, 1980). Each screening and initial experimental evaluation session lasted approximately 45-60 minutes.

The evaluations by the three speech-language pathologists took place at the Portland State University Speech and Hearing clinic. The subjects rotated from one evaluator to the next with each evaluation lasting from 10 to 20 minutes. These evaluations took place within three weeks of the initial screening session.

\section{Data Scoring and Analysis}

All standardized testing instruments were scored according to the scoring procedures outlined in their respective manuals. The three speech-language pathologists rated each subject on a probability scale from 0 to 100 percent with 100 indicating a high probability of demonstrating apraxia of speech. Along with the rating, each evaluator was instructed to list the characteristics they observed to substantiate the rating they placed on each subject. See Appendix $C$ for a 
copy of the rating scale form provided for each evaluator.

To determine the relationship between the three evaluator pairs $(B C, B D, C D)$ the index of association used was the Pearson Product-Moment Correlation Coefficient (Pearson-r) . The resultant probability scores of the STDAS (Blakeley, 1980) were then correlated with each evaluator's rating using the Pearson-r. This correlation helped demonstrate the strength of association between pairs. To determine the actual amount of overlap between the paired variables ( $A B, A C, A D)$ in terms of shared variance, the Index of Determination was used (Ventry and Schiavetti, 1980). 
CHAPTER IV

RESULTS AND DISCUSSION

\section{Results}

The purpose of this study was to correlate the results of the Screening Test for Developmental Apraxia of Speech (STDAS) with the independent evaluations by three Speech-Language Pathologists, who have a current working knowledge in the area of developmental and/or acquired apraxia of speech, in order to determine construct validity of the STDAS as a valid predictor of Developmental Apraxia of Speech (DAS) in children. Twenty subjects, ranging in age from 4-5 to 7-7 years, participated in this study. The subjects were independently screened by four evaluators. The first evaluation was conducted by this researcher, who administered the STDAS to each subject. The other three evaluators screened each subject using their own procedures (see Chapter III), excluding the STDAS.

Table I shows the probability percentage ratings for each subject by each evaluator and the STDAS. The STDAS resulted in a probability rating for DAS on a scale from 0 to 100 percent. The three evaluators were instructed to rate each subject on probability of DAS based upon their individual methods of assessment. The evaluators' ratings also 
ranged from 0 to 100 percent.

Preliminary to analyzing the data, Pearson Product-Moment Correlation Coefficients (Pearson-r's) were computed for all three independent evaluator pairs. Resulting correlation coefficients of less than .20 indicated only a slight association among the evaluators $B, C, D$ (see Table II). The results, therefore, need to be interpreted cautiously.

\section{TABLE I}

SUMMARY OF SUBJECTS PROBABILITY PERCENTAGE RATINGS FROM THE STDAS AND

THE EVALUATORS B, C, AND D

\begin{tabular}{llrrrr}
\hline Subjects & Age & STDAS(A) & Evaluator B & Evaluator C & Evaluator D \\
\hline a & $7-7$ & 20 & 90 & 0 & 20 \\
b & $6-3$ & 0 & 0 & 0 & 20 \\
C & $5-11$ & 100 & 100 & 50 & 90 \\
d & $6-11$ & 20 & 40 & 50 & 70 \\
e & $6-2$ & 10 & 20 & 0 & 60 \\
f & $5-9$ & 100 & 20 & 20 & 80 \\
g & $6-7$ & 0 & 50 & 70 & 10 \\
h & $6-3$ & 0 & 20 & 80 & 10 \\
i & $5-8$ & 100 & 20 & 90 & 50 \\
j & $7-1$ & 100 & 70 & 70 & 50 \\
k & $7-2$ & 90 & 10 & 20 & 70 \\
l & $5-8$ & 0 & 20 & 20 & 30 \\
m & $6-2$ & 10 & 0 & 30 & 100 \\
n & $5-4$ & 100 & 10 & 70 & 50 \\
0 & $6-2$ & 0 & 0 & 20 & 20 \\
p & $4-5$ & 50 & 20 & 70 & 50 \\
q & $5-7$ & 90 & 20 & 90 & 80 \\
r & $6-2$ & 100 & 20 & 100 & 70 \\
s & $5-4$ & 100 & 70 & 90 & 70 \\
t & $5-11$ & 100 & 10 & 50 & \\
& & & & & \\
\hline
\end{tabular}

The question investigated in this study was: Is the Screening Test for Developmental Apraxia of Speech a valid 
TABLE II

\section{RESULTING PEARSON-r'S, STANDARD DEVIATIONS \\ AND MEANS OF THE THREE INDEPENDEITT \\ EVALUATOR PAIRS (BC, BD, CD)}

\begin{tabular}{llllll}
\hline & SdX & SdY & $\bar{X}$ & $\bar{Y}$ \\
\hline BC & .12 & 29.81 & 33.47 & 30.50 & 49.50 \\
BD & .08 & 29.81 & 28.55 & 30.50 & 50.50 \\
CD & .18 & 33.47 & 28.55 & 49.50 & 50.50 \\
\hline
\end{tabular}

predictor of Developmental Apraxia of Speech (DAS) in children when correlated with independent evaluations by three Speech-Language Pathologists, who have a current working knowledge of the disorder of developmental and/or acquired apraxia of speech?

The Pearson-r was utilized to determine strength of association between the STDAS ratings and the evaluator ratings (see Table III). The strength of relationship depicted by the Pearson-r between each pair (independent evaluator with the STDAS, i.e., evaluator $A$ ) was as follows: $A B$ with a Pearson-r of .20 demonstrated a slight correlation; AC with a Pearson-r of .50 demonstrated a moderate correlation; and $A D$ with a Pearson-r of .73 demonstrated a high correlation.

Table IV represents the Pearson-r's of all possible pairs $(B C, B D, C D, A B, A C$, and $A D)$. The data in this table have been reported previously, but are presented here to give the reader an overall picture of the strength of association 


\section{TABLE III}

RESULTING PEARSON-r'S, STANDARD DEVIATIONS

AND MEANS BETWEEN THE STDAS RATINGS AND

THE INDEPENDENT RATINGS OF THE

THREE EVALUATORS

\begin{tabular}{llllll}
\hline \hline Pairs & $r$ & SdX & SdY & $\bar{X}$ & $\bar{Y}$ \\
\hline AB & .20 & 46.05 & 29.81 & 54.50 & 30.50 \\
AC & .50 & 46.05 & 33.47 & 54.50 & 49.50 \\
AD & .73 & 46.05 & 28.55 & 54.50 & 50.50 \\
\hline
\end{tabular}

TABLE IV

A CORRELATION MATRIX OF THE FIVE VARIABLES

SHOWING THE STRENGTH OF ASSOCIATION

BETWEEN ALL POSSIBLE PAIRS

\begin{tabular}{ccccc}
\hline Variable & A & B & C & D \\
\hline STDAS A & - & .20 & .50 & .73 \\
Evaluator B & .20 & - & .08 & .12 \\
Evaluator C & .50 & .08 & - & .18 \\
Evaluator D & .73 & .12 & .18 & - \\
\hline
\end{tabular}

between pairs.

A one-tailed $\underline{t}$ test was calculated on the four pairs of variables. Two out of the three correlation coefficients were significant beyond the .05 level of confidence (see Table V).

To determine the actual amount of overlap between the paired variables $(A B, A C, A D)$ in terms of shared variance, the Index of Determination was used (Ventry and Schiavetti, 1980). 
TABLE V

RESULTS OF THE $t$-TEST OF THE DIFFERENCES BETWEEN THE ST̄DAS AND THE INDEPENDENT

MEASURES OF THE EVALUATORS

\begin{tabular}{ccc}
\hline Pairs & r & t-values* \\
\hline AB & .20 & .87 \\
AC & .50 & $2.44 * *$ \\
AD & .73 & $4.49 * *$ \\
\hline
\end{tabular}

* Critical value of $t=1.734$

** Significant at $.05^{-}$level of confidence

This index was obtained by squaring the correlation coefficient $\left(r^{2}\right)$. In Figure 1 , the shaded areas represent the amount of variance that overlapped or was shared by the two variables. The white area with question marks (?) indicates the variance that was not accounted for by the correlation. Further examination of Table I shows the STDAS scores to be bimodal. In other words, the scores concentrated at either end of the scale, with only one at the mid-range. The evaluators, in contrast, utilized the full range of the scale. The percent each evaluators' score was above, below and the same as the STDAS is indicated in Table VI. In fact, 55 percent of Evaluator B's scores were below the STDAS, 30 percent were above and 15 percent were the same as the STDAS. Fifty percent of Evaluator C's scores fell below the STDAS, 35 percent above and 15 percent the same as the STDAS. Evaluator D's scores were 50 percent below, 40 percent above and 10 

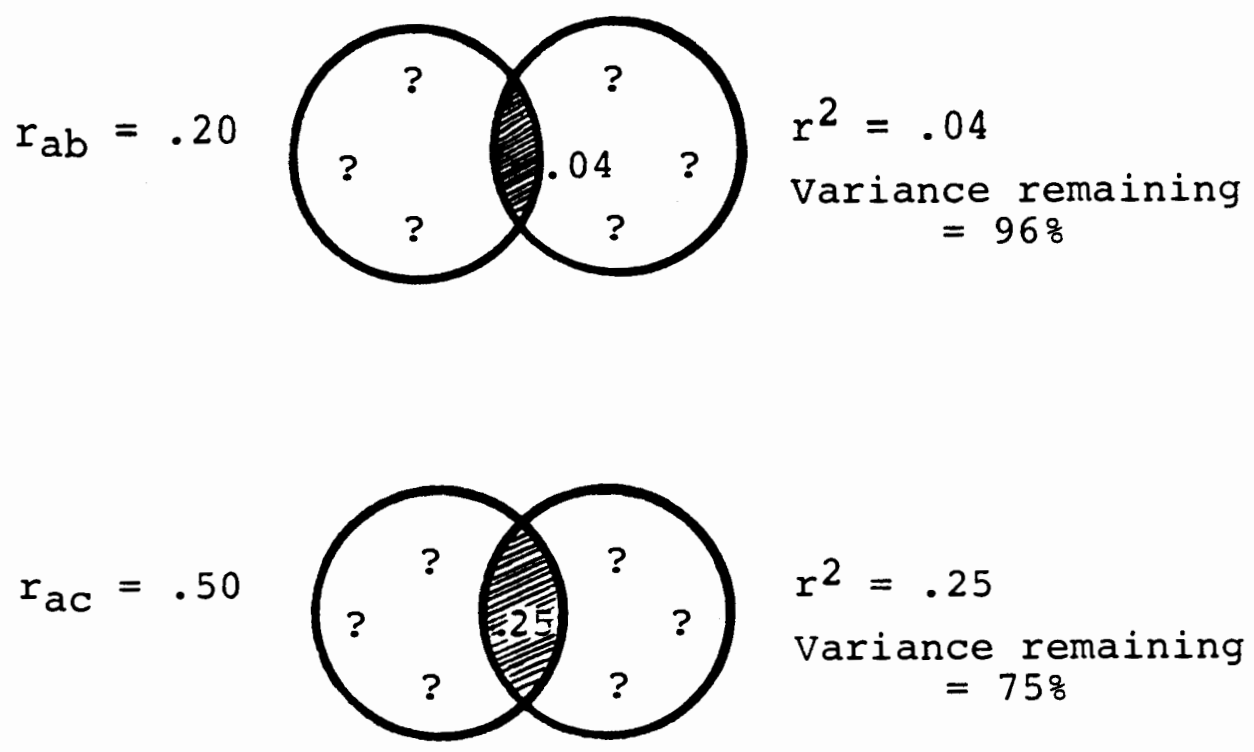

$r_{a d}=.73$

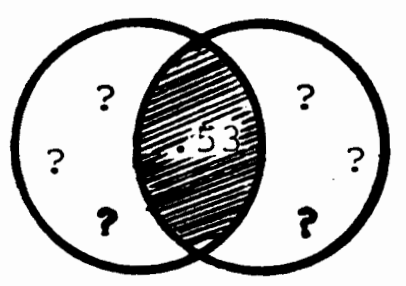

$r^{2}=.53$

Variance remaining $=47 \%$

Figure 1. The Index of Determination represents the shared variance between the paired variables. The shaded areas represent the amount of variance shared and the white areas with question marks indicate the variance that was not accounted for by the correlations.

TABLE VI

DIRECTION OF DISAGREEMENT FROM THE STDAS

\begin{tabular}{cccc}
\hline Evaluator & Below & Above & No Disagreement \\
\hline B & $45 \%$ & $30 \%$ & $15 \%$ \\
C & $50 \%$ & $35 \%$ & $15 \%$ \\
D & $50 \%$ & $40 \%$ & $10 \%$ \\
\hline
\end{tabular}


percent the same as the STDAS.

Table VII shows the percent each evaluators'scores fell into four levels of agreement with the STDAS. Agreement is indicated by 0 difference; high agreement by a range of 1 to 20; moderate agreement by a range of 21 to 40 ; and low agreement by a range of 41 to 100 percentage points difference. Evaluator B's scores agreed with the STDAS 15 percent of the time, were in high agreement 25 percent of the time, moderate agreement 15 percent of the time and low agreement 45 percent of the time. Evaluator C's scores were in agreement with the STDAS 15 percent of the time, in high agreement 35 percent of the time, moderate agreement 20 percent of the time and low agreement 30 percent of the time. Evaluator D's scores were in agreement with the STDAS 10 percent of the time, in high agreement 45 percent of the time, moderate agreement 20 percent of the time and low agreement 25 percent of the time.

\section{TABLE VII}

PERCENT EACH EVALUATORS' SCORES WERE IN AGREEMENT WITH STDAS SCORES RANGING

FROM ABSOLUTE AGREEMENT TO LOW AGREEMENT

Evaluators

Agreement

$\mathrm{High}$

Moderate

Low
B

158

$25 \%$

158

458
C

$15 \%$

$35 \%$

$20 \%$

$30 \%$
D

$10 \%$

$45 \%$

$20 \%$

25\% 


\section{Discussion}

The results of this study, at first glance, appear to support literature findings that developmental apraxia of speech (DAS) is a confusing disorder (Prichard et al., 1979). The Pearson-r showed a slight positive correlation between the evaluators. In other words, the evaluators only slightly agreed with one another.

In correlating each evaluator with the screening Test for Developmental Apraxia of Speech (STDAS), however, the results were more encouraging. The correlations between the STDAS (A) and the individual evaluators (B, C, D) ranged from a slight correlation for $A B(.20)$ to a high correlation for $A D(.73)$. The fact that the correlations between the STDAS (A) and the evaluators (B, C, D) were higher than the correlations among the evaluators may indicate that the STDAS tapped more of the components of DAS (in the sense of comprehensiveness) than any single evaluator measure. One explanation of the wide range of correlation coefficients $(.20$ to .73$)$ is the STDAS is an objective measure whereas, the evaluators' screening procedures varied in the amount of structure involved. Through observation, this researcher subjectively ranked each evaluator's screening procedure as low (evaluator B), moderate (evaluator C) and highly structured (evaluator D). Evaluator B used the least amount of structure. This evaluator used no instruments or materials other than a 
pencil and summary sheet provided by this researcher. This evaluator's screening procedure lasted from five to fifteen minutes for each subject. Evaluator C used a screening process of moderate structure, utilizing a standardized articulation test, tongue blades, pencil and the summary sheet provided. This evaluator's screening lasted from ten to twenty minutes for each subject. Evaluator $D$ used the most structure of the three evaluators. This evaluator developed a screening tool which was used for each subject, modified slightly depending upon the age of the subject, resulting in a numerical rating upon which evaluator $D$ based the probability rating. This evaluator's screening lasted approximately twenty minutes for each subject.

A second factor likely contributing to lack of agreement among the evaluators was the fact that parent interviews or case histories of each subject were not available to the evaluators. All three evaluators stated that they rely heavily upon a child's past history for differential diagnosis of DAS. As the literature indicates, children with DAS have a history of delayed speech acquisition, including little early vocal play (Eisensen, 1972; Rosenbek and Wertz, 1972). Ferry et al. (1974) found that DAS is often associated with a familial history of speech disorders. This information was not available to the evaluators to help them rank each subject. Case histories were not provided because the STDAS does not take into account the child's case history, when calculating the probability rating. 
In addition to rating each subject, the evaluators were instructed to list three to four characteristics they observed to support the rating given to each particular subject. For each evaluator's rating of 50 percent or greater the characteristics listed were tallied. The six characteristics listed most often among the evaluators were: (1) difficulty in sequencing phonemes (diadochokinesis rate and multisyllabic words), (2) deviant rather than immature phoneme error patterns, (3) effortful oral-motor movement in accurate placement of the articulators, (4) overall intelligibility is poor, (5) inconsistent articulation errors, and (6) vowel distortions. This researcher then compared these six most often listed characteristics of DAS by the evaluators with the list developed by Williams et al. (1981b). All four of the characteristics agreed upon as being only associated with DAS in the Williams et al. study were included in this list (see Chapter II, p. 11).

In reviewing each of the evaluator's lists, it was interesting to note that even though they were in general agreement about what characteristics constituted DAS, their perceptions of each subject were quite varied. Again, the fact that each evaluator used a different amount of structure during their screening, may explain the inconsistencies among their results. The less the structure, the more the evaluators had to rely on their clinical experience and "gut level" judgment. In contrast, the evaluators using more structure, not only made their decision on subjective information, but 
on objective data as well.

When comparing the STDAS (an objective measure) results with the results of evaluator $D$, who used an objective procedure of assessment, the correlations were high (see Table III and Figure 1.). Evaluator $D$ had the advantage of combining clinicial judgment and the objective data obtained from the assessment tool used. The STDAS evaluation, however, ranked each subject solely on the objective results obtained.

The inconsistency among the evaluators' assessments is an excellent argument for a screening instrument that uses the current body of knowledge concerning DAS. Considering the available test batteries, the characteristics agreed upon in the literature, clinical experience, support of experts in the field and availability of normative data, Blakeley (1980) developed such a tool. Blakeley intended the STDAS to be used as a screening instrument to assist in the differential diagnosis of DAS. The STDAS is not to be used to label or diagnose DAS in children. The information gained from the test is to be used in determining the need for further investigation (Blakeley, 1980).

The resulting data of this study supports Blakeley's intention for the STDAS to be used as part of a differential diagnosis of DAS. When combined with other measures, such as, case history, clinical judgment and neurological assessment, the STDAS can play an important contributing role in differentiating DAS from other articulatory disorders.

A recent article by Guyette and Diedrich (1983) 
identified several limitations of the STDAS. One drawback cited was the fact that no attempt was made to validate this instrument. In the article they suggest a way to validate such a test for DAS, i.e., select a panel of speech-language pathologists, agree on certain apraxic children and then give these children the STDAS for comparison. The present study followed a validation procedure opposite of this suggestion, assessing not just probable apraxic children but a range from no probability of belonging to an apraxic group to a high probability of belonging to an apraxic group. No other issues brought out in the Guyette and Diedrich article are addressed in this study. 
CHAPTER V

SUMMARY AND IMPLICATIONS

\section{Summary}

The term "developmental apraxia of speech" (DAS) has been a confusing one since Morley, Court and Miller (1954) first applied it to articulatory patterns of a specific group of children (Prichard, Tekieli, and Kozup, 1979). The lack of well-defined research on DAS has even led to controversy over the existence of this disorder (Haynes, 1978; Guyette and Diedrich, 1983). Despite the controversy, many labels have been applied to a group of chidlren displaying similar characteristics, such as highly unintelligible speech; failure to improve even with extensive intervention; hearing within normal limits; age appropriate receptive language; and groping and struggling to achieve correct positioning of the articulators (Ferry et al, 1974).

Until recently, the differentiation of diagnositc features of DAS in children as compared to other articulatory disorders has been difficult. One evaluation tool, developed by Blakeley (1980), to assist in differential diagnosis of DAS is the Screening Test for Developmental Apraxia of Speech (STDAS). This study examined the validity of this tool by comparing its results with the evaluation by three speech- 
Language Pathologists knowledgeable in the area of developmental and/or acquired apraxia of speech.

Twenty subjects, ranging in age from 4-5 to 7-7 years, participated in this study. The subjects were independently screened by four evaluators. The first evaluation was conducted by this researcher, administering the STDAS to each subject. The other three evaluators screened each subject using their own procedures, excluding the STDAS. The STDAS resulted in a probability rating for DAS. The three evaluators were instructed to rate each subject on probability of DAS based upon their individual methods of assessment.

Pearson-r's were computed on all three independent evaluator pairs. The evaluators only slightly agreed with one another. Although they were in general agreement as to what characteristics constitute DAS, their perceptions of each subject were quite varied.

In correlating the STDAS (A) with each evaluator (B, C, D) the results ranged from slight correlation of $A B$ to high correlation of $\mathrm{AD}$. This outcome may indicate that the STDAS tapped more of the components of apraxia (in the sense of comprehensiveness) than any single evaluator measure.

Two factors seemed to contribute to the varied results among evaluators: (1) lack of information about the subjects' history of development, including familial history and management history; and (2) varied amount of structure used among the evaluators. When comparing the STDAS results with an evaluator who used a highly structured method of assessment, 
the correlation was high. This evaluator had the advantage of objective data, as well as, clinical judgment to base the final rating for each subject.

The inconsistency among the evaluators' assessment results is an excellent argument for a screening instrument that uses the current body of knowledge concerning DAS. The resulting data of this study support Blakeley's (1980) intention for the STDAS to be used as part of a differential diagnosis of DAS. When combined with other measures, such as case history, clinical judgment of examiner, as well as colleagues and neurological assessment, the STDAS can play an important contributing role in differentiating DAS from other articulatory disorders.

\section{Implications}

$\underline{\text { Research }}$

The age range of the STDAS is from 4 to 12 years. This study only used subjects ranging in age from 4 to 8 years. A similar study could be conducted using subjects at the upper age range from 8 to 12 years.

The original premise of having the three evaluators independently assess each subject using their own methods was to determine how evaluations of DAS by speech-language pathologists in the field compared to evaluation using the STDAS. As the results of this study indicate, the more objective the evaluator's method, the higher the correlation with the STDAS. In replicating this study, one possible change would be to 
meet with the evaluators and develop a screening tool all would use. This tool would be developed collectively from agreed-upon characteristics. The evaluators would then have the advantage of an objective tool, as well as their clinical judgments.

In replicating this study adding a case history to the evaluation procedure would be interesting. The evaluators in this study were unanimous in needing a case history of each subject before making their decision.

A replication of the Williams, Packman, Ingham and Rosenthal (1981b) study, which was designed to find some agreement among speech-language pathologists on behaviors they judged distinguished DAS, would be interesting. They surveyed 31 clinicians in the Sidney, Australia area. Doing a similar study in the oregon and Washington area would be very valuable.

As Guyette and Diedrich (1983) have suggested, one way to validate this tool would be to have a panel of speech-language pathologists agree on certain apraxic children and then give these children the STDAS for comparison.

\section{Clinical}

The results of this study have shown that clinical judgment alone in distinguishing DAS is not reliable. The inconsistency among the evaluators' assessments, however, lends support to using a screening instrument that utilizes the current body of knowledge concerning DAS. The STDAS forces 
the examiner to assess the child more objectively. Although all three evaluators were looking for the same characteristics in each child, the evaluator with the most objective procedure correlated the highest with the STDAS. The results of this study support Blakeley's intention for the STDAS to be used as part of a differential diagnosis of DAS. When combined with other measures, such as case history, clinical judgment and neurological assessment, the STDAS can play an important contributing role in differentiating DAS from other articulatory disorders. 


\section{REFERENCES}

ATEN, J., JOHNS, D., and DARLEY, R. (1971). Auditory perception of sequenced words in apraxia of speech. Journal of Speech and Hearing Research, 14, 131-143.

BERNTHAL, J. and BANKSON, N. (1981). Articulation disorders. NJ: Prentice-Hall.

BLAKELEY, R. (1980). Screening test for developmental apraxia of speech. Tigard, OR: C.C. Publications.

BLAKELEY, R. (1982). Notes from meeting with Dr. Blakeley on the topic of Developmental apraxia of speech, May.

DABUL, B. and BOLLIER, B. (1976). Therapeutic approaches to apraxia. Journal of Speech and Hearing Disorders, 41, $268-276$.

DARLEY, F. (1964). Diagnosis and appraisal of communication disorders. Englewood Cliffs, NJ: Prentice-Hall, Foundations of Speech Pathology Series.

DARLEY, F. (1969). The classification of output disturbances in neurologic communication disorders. In Johns, Clinical management of neurogenic communicative disorders. Boston: Little, Brown and Company, 1978.

DARLEY F. (1975). Developmental articulatory problems. Australian Journal of Human Communication Disorders, $3(1)$, 47-54.

DARLEY, F., ARONSON, A. and BROWN, J. (1975). Motor speech disorders. Philadelphia: W.B. Saunders Co.

DARLEY, F. and SPRIESTERSBACH, D. (1978). Diagnostic methods in speech pathology. NY: Harper and Row (2nd ed.).

DUNN, L. (1981). Peabody picture vocabulary test-revised. Circle Pines: American Guide Service.

EDWARDS, M. (1973). Developmental verbal dyspraxia. British Journal Disorders of Communication, 64-70.

EISENSEN,J. (1972). Aphasia in children. NY: Harper and Row. 
FERRY, P., HALL, S. and HICKS, J. (1974). Verbal dyspraxia in children: A neurological cause of "poor speech." Journal of oregon Speech and Hearing Association, 13, 14-19.

FUDALA, J. (1982). Arizona articulation proficiency scale: Revised. Los Angeles: Western Psychological Services (9th ed.).

GORDON, M. (1982). Childhood dyspraxia intervention. A workshop in Coos Bay OR.

GUYETTE, T. and DIEDRICH, W. (1983). A review of the screening test for developmental apraxia of speech. Language, Speech and Hearing Services in Schools, 14, 202-209.

HAYNES, S. (1978). Developmental apraxia of speech: Symptoms and treatment. In D.F. Johns, Clinical management of communicative disorders. Boston: Little, Brown and Company.

HEJNA, R. (1963). Developmental articulation test. Ann Arbor MI : Speech Materials.

HOROWITZ, A. (1979). The effects of three stress modes on error productions of children with developmental apraxia of speech. Unpublished master's thesis, Portland State University, Portland OR.

JOHNS, D. (1978). Clinical management of communicative disorders. Boston: Little, Brown and Company.

JOHNSON, J. (1980). Nature and treatment of articulation disorders. Springfield: Charles C. Thomas.

MCCARTHY, D. (1954). Language development in children. In Mussen Carmichael's (Ed.), Manual of child psychology. NY: John Wiley and Sons.

MITCHAM, S. (1975). Location of dyspraxic characteristics in children with severe "functional" articulation disorders. Unpublished master's thesis, Portland State University, Portland OR.

MORLEY, M. (1965). Development and disorders of speech in childhood (2nd ed.). Baltimore: Williams and Wilkins.

MORLEY, M., COURT, D., and MILLER, H. (1954). Developmental dysarthria. British Medical Journal, 1, 8-10.

POWERS, M. (1971). Functional disorders of articulation-symptomatology and etiology. In L.E. Travis (Ed.), Handbook of speech pathology and audiology. NY: Appleton-Century-Crofts, 837-875. 
PRICHARD, C., TEKIELI, M. and KOZUP, J. (1979). Developmental apraxia: Diagnostic considerations. Journal of Communication Disorders, 12, 337-348.

ROSENBEK, J. and WERTZ, R. (1972). A review of 50 cases of developmental apraxia of speech. Language, Speech and Hearing Services in Schools, $23(3)$.

ROSENBEK, J ., HANSEN, R. , BAUGHMAN, C. and LEMME, M. (1974). Treatment of developmental apraxia of speech: A case study. Language, Speech and Hearing Services in Schools, $5(1), 13-22$.

SILVERSTEIN, B. (1971). A defective articulation syndrome characterized by consonant ommission. Paper presented at the annual convention of the ASHA, Chicago, IL.

VENTRY, I. and SCHIAVETTI, N. (1980). Evaluating research in speech pathology and audiology: $\bar{A}$ guide for clinicians and students. Philippines: Addison-Wesley.

WEINER, P. (1969). The perceptual level functioning of dysphasic children. Cortex, 5, 440-457.

WEISS, C., LILLYWHITE, H. and GORDON, M. (1980). Clinical management of articulation disorders. St Louis: The C.V. Mosby Co.

WERTZ, R. and ROSENBEK, J. (1970). Appraising apraxia of speech. Unpublished paper.

WERTZ, R. , ROSENBEK, J. and DEAL, J. (1970). A reveiw of 228 cases of apraxia of speech: Classification, etiology, and localization. Paper presented at the annual convention of the ASHA, NY.

WILLIAMS, R., ROSENTHAL, J., and INGHAM, R. (1978). Characteristics of developmental articulatory dyspraxia. In Williams, Ingham and Rosenthal (1981a), A further analysis of developmental apraxia of speech in children with defective articulation. Journal of speech and Hearing Research, 24(4), 496-505.

WILLIAMS, R., INGHAM, R. and ROSENTHAL, J. (1981a). A further analysis of developmental apraxia of speech in children with defective articulation. Journal of Speech and Hearing Research, 24(4), 496-505.

WILLIAMS, R., PACKMAN, A., INGHAM, R. and ROSENTHAL, J. (1981b). Clinical agreement on behaviors that identify developmental articulatory dyspraxia. Australian Journal of Human Communication Disorders, 8(1), 16-26. 
WOLFE, W. and GOULDING, D. (1980). Articulation and Learning. Springfield: Charles C. Thomas.

YOSS, K. and DARLEY, F. (1974a). Developmental apraxia of speech in children with defective articulation. Journal of Speech and Hearing Research, 17, 399-416.

YOSS, K. and DARLEY, F. (1974b). Therapy in developmental apraxia of speech. Language, Speech and Hearing Services in Schools, $5(\overline{1)}, 23-31$. 
APPENDIX A

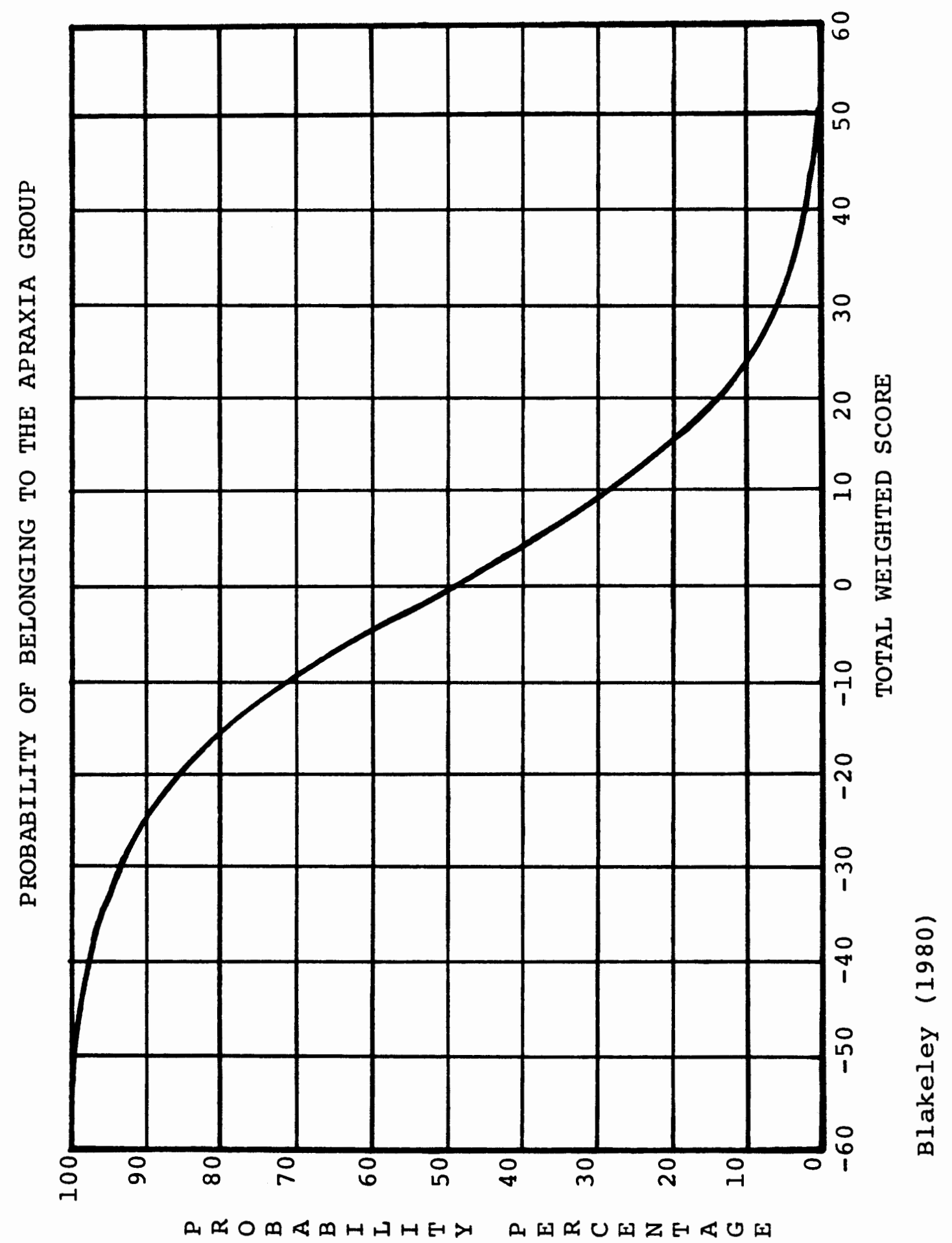




\section{APPENDIX B}

Dear Parent/Guardian,

My name is Debbie Thorsen. I am a graduate student at Portland State University in the field of Speech-Language Pathology. In partial fulfillment of my Master's degree, I am conducting a research project concerning a test used to screen children who have the speech disorder of "Developmental Apraxia." A child with "developmental apraxia" has dificulty forming the speech sounds to make words and is often difficult to understand. The test I am researching, Screening Test for Developmental Apraxia of Speech developed by Dr. Robert Blakeley in 1980, is the only one of its kind to help locate these children. Such children require unique teaching methods to learn speech. This is why it is so important to identify these children. My research involves comparing this screening test with evaluations by three speech-language pathologists knowledgeable in the area of apraxia.

I am searching for children between the ages of 4 to 8 years to help aid in this research. If you and your child participate in this study, I would need to see him/her on one occasion to do some testing. The testing would involve hearing, articulation language and administration of the Screening Test for Developmental Apraxia of speech. This would take approximately one hour and take place at your child's school. Depending on the results of the screening, your child may be selected to be evaluated by three other speech-language pathologists. This followup testing would consist of three 20-minute sessions and take place at Portland State University's Speech and Hearing Clinic. Your child would come on one occasion and see all three evaluators within an hour. I will transport your child to and from the testing site, if necessary.

Your child's name will not be used in reporting the results. Individual results may be obtained from your child's speech-language pathologist. You would, of course, be free to withdraw your child from the study at any time. There will be no charge for the evaluations.

Thank you for your consideration of this important research.

Sincerely,

Deborah I. Thorsen

Speech-Language Pathology

Masters student, PSU
Dr. Robert W. Blakeley

Speech-Language Pathologist

Crippled Children's Division 
Child's Speech-Language Pathologist

Date

No

I am not interested in my child participating in this study.

YES

I am interested in my child participating in this study and give my permission to do so.

Parent/Guardian Signature

Child's Signature ( 7 yrs and up) 
APPENDIX C

EVALUATORS RATING SCALE FORM

Name :

Age :

Low

High

$\overline{0} \overline{10} \overline{20} \overline{30} \overline{40} \overline{50} \overline{60} \overline{70} \overline{80} \overline{90} \overline{100}$

CHARACTERISTICS

COMMENTS

1 .

2 .

3.

4 . 